\title{
The Effect of Molybdenum on the Microstructure and Creep Behavior of Ti- 24Al-17Nb-xMo (at \%) and its Composites
}

\author{
J.P. Quast and C.J. Boehlert
}

Department of Chemical Engineering and Materials Science, Michigan State University, East Lansing, MI 48824

The development of superior-strength materials used in high temperature applications is necessary for the continued improvement of turbine engine systems. Orthorhombic-based intermetallic alloys, such as Ti-25Al-17Nb (at\%), have displayed excellent intermediate-temperature strength [1] and creep resistance [2]. However, further improvement in creep behavior may be obtained by altering the microstructure. The addition of molybdenum (Mo), a beta-phase stabilizer, affects the grain size and the constituent phase volume fractions. Small Mo additions of 1 at $\%$ have all resulted in significant creep property improvements [3-5]. In this work, we evaluated the effect of Mo contents ranging between $0.66-2.3 \mathrm{Mo}$ on the microstructure and creep behavior of a Ti-24Al-17Nb (at \%) alloy. In addition, we evaluated the effect of such Mo contents on the microstructure and creep behavior of Ti-25Al-17Nb-XMo matrices which were reinforced with approximately 37 volume percent continuous silicon carbide fibers.

The microstructures of Ti-24Al-17Nb-0.66Mo and Ti-24Al-17Nb-2.25Mo (at \%) alloys were analyzed using a Camscan 44FE field emission scanning electron microscope. Increases in Mo concentration led to a decrease in the hexagonal close packed (hcp) $\alpha_{2}$ phase volume fraction and an associated increase in orthorhombic and body centered cubic (bcc) phase volume fraction, as shown in Fig. 1. The volume fractions of the Ti-24Al-17Nb-0.66Mo alloy were $38.3 \% \alpha_{2}$ and $61.7 \mathrm{O}+$ bcc. For the Ti-24Al-17Nb-2.25Mo alloy they were $24.1 \% \alpha_{2}$ and $75.9 \% \mathrm{O}+$ bcc.

The affect of Mo content on creep behavior was analyzed at temperatures ranging from $650^{\circ} \mathrm{C}$ to $710^{\circ} \mathrm{C}$ and stresses ranging from $30-275 \mathrm{MPa}$. The Ti-24Al-17Nb-2.25Mo alloy exhibited superior creep resistance compared with the Ti-24Al-17Nb-0.66Mo alloy, as shown in Fig. 2(b). In fact, approximately one order of magnitude difference in minimum creep rate was observed at all stresses evaluated at $650^{\circ} \mathrm{C}$. Thus, small changes in Mo concentration significantly affect the creep behavior of Ti-Al-Nb alloys. Using an Ernest Fullam tensile stage, samples were imaged in-situ during the creep experiment. From such experiment, the deformation in the form of cracking was observed at $\alpha_{2}$ grain boundaries, see Fig. 2(a). Thus, reducing the continuity and size of the $\alpha_{2}$ phase through the addition of small amounts of Mo can have a significant effect on the creep behavior. This trend will be investigated in the metal matrix composite samples, which will be evaluated with the fiber direction both perpendicular and parallel to the loading direction.

References

[1] C.J. Boehlert, Metall. Mater. Trans. A. 30A (1999) 2349.

[2] C.J. Boehlert, D.B. Miracle, Metall. Mater. Trans. A. 32A (2001) 1977.

[3] S. Krishnamurthy et al., Proceedings from the $10^{\text {th }}$ International Conference of Composite Materials. 2 (1995) 739.

[4] P.R. Smith, Proceedings from Orthorhombic Titanium Matrix Composite Workshop, WrightPatterson Air Force Base, Cincinnati, 1994. 
[5] S. Krishnamurthy et al., Orthorhombic Titanium Matrix Composites Workshop, WrightPatterson Air Force Base, Cincinnati, 1994.

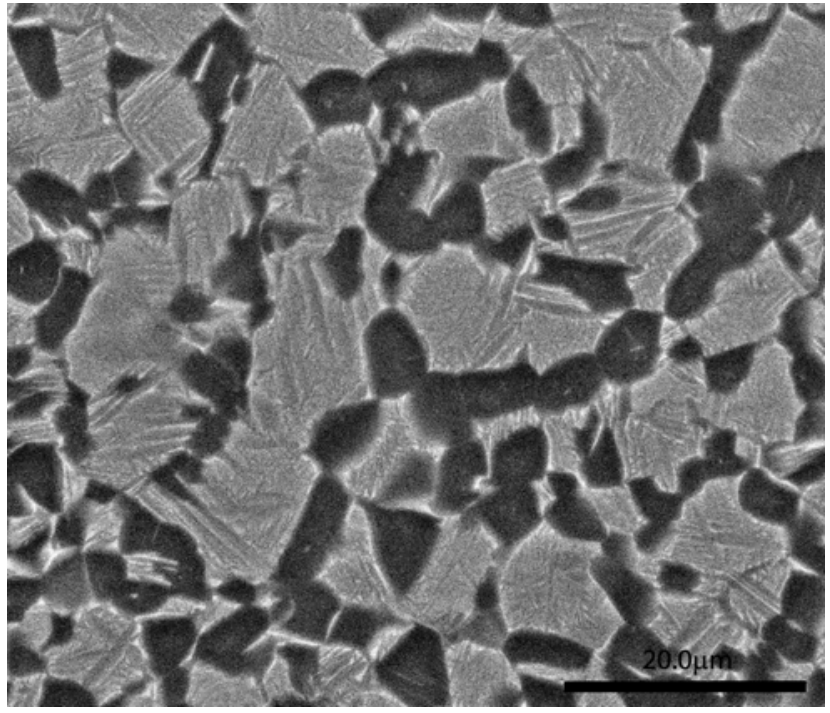

(a)

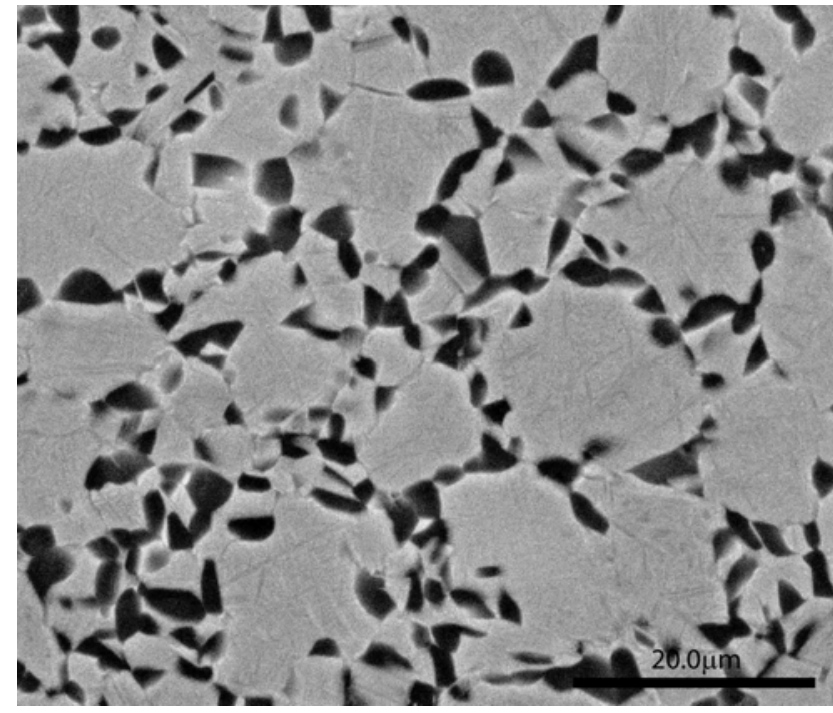

(b)

FIG. 1. Backscattered SEM images taken for (a) Ti-25Al-17Nb-0.66Mo (at \%) and (b) Ti-25Al$17 \mathrm{Nb}-2.3 \mathrm{Mo}(\mathrm{at} \%)$ after heat treatment at $1050^{\circ} \mathrm{C}$ for $1 \mathrm{~h}$, control cooled to $850^{\circ} \mathrm{C}$ and held for $2 \mathrm{~h}$, control cooled to $650^{\circ} \mathrm{C}$, and furnace cooled to room temperature. Note that the higher Mo content alloy exhibited lower hep $\alpha_{2}$ (dark) phase volume fraction and larger orthorhombic (gray) and bcc (light) phase volume fraction.

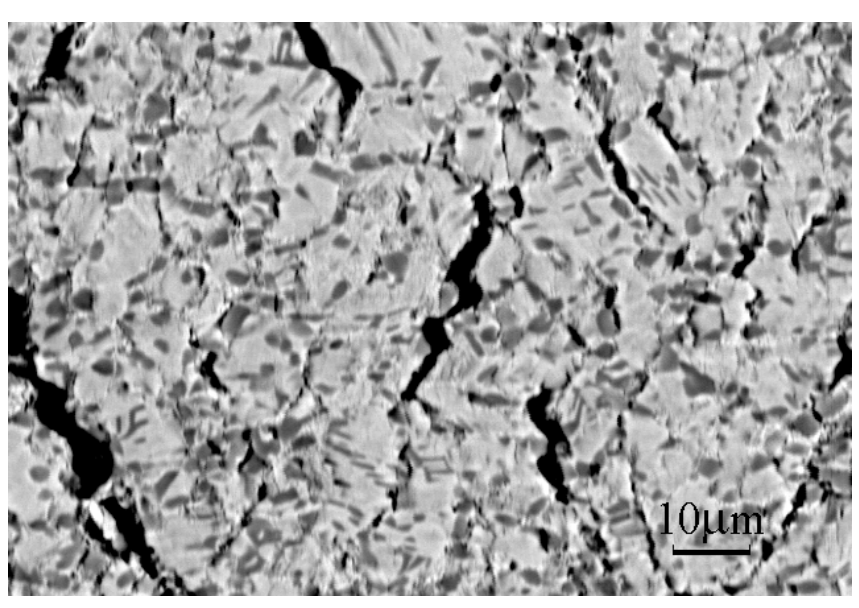

(a)

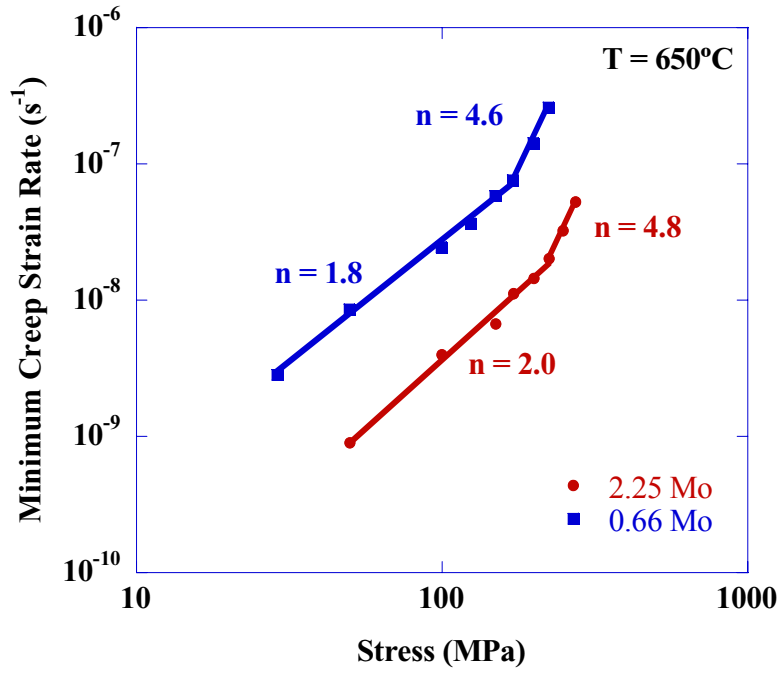

(b)

FIG. 2. A backscattered SEM image taken during an in situ creep experiment for Ti-24Al-17Nb2.3Mo (at $\%)$ at $705^{\circ} \mathrm{C}$ and $150 \mathrm{MPa}$. Note the cracks tended to follow the $\alpha_{2}$ grain boundaries. (b) The minimum creep strain rate vs. applied stress for each alloy. The Ti-24Al-17Nb-2.3Mo alloy exhibited nearly an order of magnitude decrease in minimum creep rate. Both alloys exhibited a change in $\mathrm{n}$ at an applied stress between 170-225 $\mathrm{MPa}$, suggesting that at least two dominant secondary creep mechanisms may be active. 